Review Article

Archives of Disease in Childhood, 1972, 47, 683.

\title{
Regulation of Erythropoiesis in the Fetus and Newborn
}

\author{
PER HAAVARDSHOLM FINNE and SVERRE HALVORSEN \\ From the Paediatric Research Institute, Barneklinikken, Rikshospitalet, Oslo, Norway
}

The present concept of the regulation of erythropoiesis is based on the theory that a humoral factor, erythropoietin, stimulates red cell production through its effects on the erythropoietin sensitive stem cell, on DNA synthesis in the erythroblast, and on the release of reticulocytes (Gordon and Zanjani, 1970; Hodgson, 1970). Erythropoietin production is regulated by the difference between oxygen supply and demand within the oxygen sensitive cells in the kidney. As a response to hypoxia, a factor called erythrogenin is produced in the kidney. This factor acts on a serum substrate to generate an active humoral factor, the erythropoietic stimulating factor (ESF) or erythropoietin (Gordon, 1971), increased amount of which leads to increased red cell production.

Many details in this theory are still a matter of controversy, as for example where in the kidney erythrogenin is produced, where the active ESF is generated, whether the kidney is the sole site of $\mathrm{O}_{2}$-tension registration and of erythrogenin production, and whether the active ESF is the only factor involved in the regulation of red cell production. Some data, for instance, indicate a more complicated model, and an erythropoietic inhibitory factor has been postulated whereby increased erythropoiesis could also result from a decrease of the inhibiting factor (Krzymowski and Krzymowska, 1962; Skjælaaen and Halvorsen, 1971; Lindemann, 1971).

\section{Fetal Erythropoiesis}

Erythropoiesis takes place at three main sites during fetal life; the yolk sac, the liver, and the bone marrow (Yoffey, 1971). In general, erythropoiesis at the yolk sac stage, which is predominantly megaloblastic, ceases by the end of the first trimester. Hepatic erythropoiesis then takes over and becomes dominant until the beginning of the third trimester. It is at this time that bone marrow erythropoiesis begins, but the hepatic erythropoiesis continues until a few days after birth. At birth, erythropoie- sis in the human is predominantly myeloid during normal conditions. In other species (mice, rats) it is different, with the shift from hepatic to myeloid stage occurring after birth (Lucarelli, Howard, and Stohlman, 1964; Stohlman, 1970).

A progressive increase in erythrocyte content per $\mathrm{ml}$ and in $\mathrm{Hb}$ concentration has been found in human blood during the course of intrauterine development, leading to the normal high values at birth (Thomas and Yoffey, 1962; Walker and Turnbull, 1953). Marks, Gairdner, and Roscoe (1955), however, found no increase in $\mathrm{Hb}$ values with gestational age after 31 weeks gestation. The alteration in $\mathrm{Hb}$ structure during intrauterine and early neonatal life changes its physical properties (de Verdier and Garby, 1969; DelivoriaPapadopoulos, Poncevic, and Oski, 1971). Hb-F has a left-shifted oxyhaemoglobin dissociation curve, i.e. the affinity between $\mathrm{Hb}-\mathrm{F}$ and oxygen is high, which makes $\mathrm{Hb}-\mathrm{F}$ more suitable for providing oxygen transport to the fetus from the placenta. Though delivery of oxygen to peripheral fetal tissue must be affected due to this high affinity, other compensating mechanisms secure sufficient tissue oxygenation. The polycythaemia of the fetus is probably the most important factor.

Mention should be made here of the major differences to be found between $\mathrm{Hb}-\mathrm{F}$ and $\mathrm{Hb}-\mathrm{A}$ in their reactions with certain organic phosphorus compounds in the red cell. 2,3-diphosphoglycerate (DPG) interacts with the $\mathrm{Hb}$ molecule changing its stereotactic properties and thus its affinity for oxygen, i.e. the oxyhaemoglobin dissociation curve. $\mathrm{Hb}-\mathrm{F}$ interacts nearly as effectively as $\mathrm{Hb}-\mathrm{A}$, however, so that this factor turns out to be not very important in the present context (de Verdier and Garby, 1969).

Experiments in sheep favour the idea that $\mathrm{Hb}-\mathrm{F}$ is superior to $\mathrm{Hb}$-A for transport of oxygen through placenta. Exchange transfusion in sheep fetuses using adult sheep blood resulted in a decrease in 
oxygen affinity of the fetuses' blood and a decrease in its oxygen saturation. A reticulocytosis also occurred in the fetus after such an exchange transfusion, though the $\mathrm{Hb}$ concentration (oxygen carrying capacity) was the same as before transfusion (Battaglia et al., 1969).

Adult $\mathrm{Hb}$ is first detected in the fetus at the 13th week of gestation and increases in concentration until birth to approximately 20 to $30 \%$ of the total $\mathrm{Hb}$. A rapid decline in $\mathrm{Hb}-\mathrm{F}$ is noted during the first months until the normal adult level of about $2 \%$ is reached at the age of 5 months (Bertles, 1970).

\section{Regulation of Fetal Erythropoiesis}

While much is known of the morphology of fetal erythropoiesis, little is known about its regulation. It seems to be quite independent of the mother, though maternal hypoxic conditions (anaemia or hypoxia) may activate fetal compensatory mechanisms. In man, ESF is found in fetal blood during the last trimester, and in increased amounts when increased need for red cells is present as in erythroblastosis fetalis (Finne, 1966). A rise in ESF level in the blood is also found in the normal fetus with increasing gestational age, leading to a high level in cord blood at term (Halvorsen and Finne, 1968). According to the theory of ESF regulation of erythropoiesis, this indicates the presence of a hypoxic stimulus in the near term fetus. At delivery a sharp decline in blood ESF level is demonstrable in agreement with the rapid change in oxygen supply to the newborn.

The fetus thus seems to have the ability to compensate for hypoxaemia. The compensation occurs whether the cause of hypoxaemia is in the fetus itself (anaemia), the placenta (reduced perfusion), or the mother (anaemia, hypoxaemia), since increased ESF levels are found in fetal blood when fetal anaemia is present, in placental dysfunction, and in maternal hypoxaemia (Finne, 1966). The available data are conflicting regarding the occurrence of polycythaemia in cases of placental dysfunction and of postmaturity (Humbert et al., 1969; Usher and Lind, 1965; Walker and Turnbull, 1953). The aetiology of neonatal polyglobulia (i.e. venous haematocrit $>70$ ) is thus largely unknown, though several causes have been postulated. A lack of an inhibitor in the urine of these patients has been shown (Lindemann and Halvorsen, 1971), but this needs confirmation.

The composition of the liquor amnii reflects in many ways the state of the fetus. In the last trimester of pregnancy ESF has been detected in liquor and it has been shown that the level in the liquor reflects the ESF levels in fetal blood. The transfer of ESF from the fetus to the liquor is thought to be through the urine, since a correlation is found between ESF content in fetal blood, urine, and liquor (Finne, 1964). These clinical findings in man imply that ESF plays an important role in the regulation of red cell production during intrauterine life, at least in the third trimester.

Experiments in animals confirm this conclusion, since the fetus is able to react with increased ESF formation when fetal anaemia is induced by phenylhydrazine (Zanjani and Gordon, 1971). Additional evidence for the importance of ESF in fetal erythropoiesis is the depression of red cell production in the fetus when erythropoietin antiserum is injected into the mother (Schooley et al., 1968). But whether ESF is the sole regulator of fetal erythropoiesis, and whether ESF is active during all three stages of fetal erythropoiesis are questions that remain unanswered. The available data in man mostly relate to the last trimester and thus to the myeloid stage. Whether ESF is of the same importance during the yolk sac and hepatic stages of erythropoiesis as in the myeloid stage is questionable according to animal experiments. Recent work in mice indicates that yolk sac erythropoiesis is insensitive to ESF, while the hepatic erythropoiesis is sensitive to ESF at least during some period of intrauterine life (Cole and Paul, 1966).

In man, recent studies (Basch, 1972) indicate that fetal liver erythropoiesis is also sensitive to ESF as it is in the mouse.

\section{The Kidney and Fetal Erythropoiesis}

The question of the kidney as the production site of ESF during intrauterine life is also a matter of debate. Since red cell formation antedates the development of the kidney, the initiation of erythropoiesis and its regulation at the yolk sac stage cannot be governed by ESF produced in the kidney, though it could be produced in the kidney anlage. The influence of maternal ESF is unlikely, since maternal polycythaemia (i.e. suppressed maternal erythropoietin) does not influence fetal red cell formation (Jacobson, Marks, and Gaston, 1959). Data from adults imply that the kidney is not the sole site of ESF formation, since erythropoiesis in anephric man continues though at a much reduced rate, and hypoxia still elicits a rise in ESF levels (Nathan et al., 1964). However, species differences are found. Nephrectomy in the dog (Naets, 1960) and the rat suppresses erythropoiesis almost entirely. The authors know of no thorough investigation of erythropoiesis in cases of bilateral renal agenesis in man, but our observations on a 
single case suggest that hepatic erythropoiesis is functioning at birth and that there is no anaemia. Further studies on such cases will be of great interest.

\section{Neonatal Period}

Erythropoiesis markedly decreases during the first week of extrauterine life. Studies of bone marrow (Kalpaktsoglou and Emery, 1965), reticulocytes (Seip, 1955), and iron kinetics (Garby, Sjölin, and Vuille, 1962) all support this. By adult standards, raised ESF levels are found in cord blood at term, while no ESF can be detected in blood or urine from the second day of extrauterine life and during the following 6 to 8 weeks (Halvorsen, 1963; Mann et al., 1965; Lindemann and Halvorsen, 1971). The time relation of the decline in erythropoiesis fits nicely with the expected decline derived from the assumption that ESF production ceases at or shortly after birth. It is, therefore, well substantiated that the decrease in erythropoiesis during the first week is due to improved oxygenation of the tissues and cessation of ESF production. The finding of erythropoiesis inhibitors in the plasma of newborn infants from the 4th day of life may suggest that inhibitory mechanisms are also operating in the suppression of erythropoiesis postnatally (Skjælaaen and Halvorsen, 1971; Lindemann and Halvorsen, 1971).

During the next weeks erythropoiesis continues at a low rate and red cell destruction exceeds production. In term infants $\mathrm{Hb}$ falls to a level of about $11 \mathrm{~g} / 100 \mathrm{ml}$ at 3 months, then increases to about $12 \mathrm{~g}$ at 12 months (Moe, 1963). Total red cell volume (RCV) decreases until about the end of the second month of life. RCV increases again from that time to reach the volume at delivery at the end of the fifth month. $\mathrm{RCV} / \mathrm{kg}$ is, however, constant from the end of the second month (Bratteby, 1968).

Beginning in the late intrauterine period and continuing during neonatal life, a marked decline in $\mathrm{Hb}-\mathrm{F}$ is found, with a concomitant increase in $\mathrm{Hb}-\mathrm{A}$. The normal adult values of $\mathrm{Hb}-\mathrm{A}$ are found at 4 to 5 months of age. How the switches through the different $\mathrm{Hbs}$ in fetal life are regulated is unknown. ESF stimulates production of both $\mathrm{Hb}-\mathrm{F}$ and $\mathrm{Hb}-\mathrm{A}$. The switches do not seem to be related to erythropoietin (Bertles, 1970).

Because of the difference in oxygen affinity, the change from $\mathrm{Hb}-\mathrm{F}$ to $\mathrm{Hb}-\mathrm{A}$ leads to a right shift of the oxygen- $\mathrm{Hb}$ equilibrium curve during the first months of life. The curve becomes similar to that in the normal adult between 4 and 6 months of life. However, there seems to be little correla- tion between the decrease in the oxygen affinity in neonatal life and the percentage of $\mathrm{Hb}-\mathrm{F}$, but more with the product of 2,3-DPG and Hb-A concentration (Oski and Delivoria-Papadopoulos, 1970).

In this context the right shift of the oxyhaemoglobin equilibrium is of great interest. For example, an infant aged 2 months with a $\mathrm{Hb}$ level of $12 \mathrm{~g} / 100 \mathrm{ml}$ is able to deliver at least the same amount of oxygen to the tissues as the newborn with an $\mathrm{Hb}$ level of $17 \mathrm{~g} / 100 \mathrm{ml}$ (Delivoria-Papadopoulos et al., 1971). This right shift seems to account for normal oxygen delivery to the tissue during early life, despite the decline in $\mathrm{Hb}$ concentration.

During the first weeks of life the relative polycythaemia and the shift of the oxyhaemoglobin dissociation curve to the right together provide sufficient oxygen to the tissues, and lead to decreases in erythropoietin production, in red cell formation, and in red cell volume per $\mathrm{kg}$, until the second month of life.

Infants with congenital cyanotic heart disease have high levels of ESF in blood during the first weeks of life (Halvorsen, 1963) and develop polycythaemia as a result of the increased stimulus for red cell formation (Gairdner, Marks, and Roscoe, 1952). This shows that hypoxic hypoxia stimulates ESF production and erythropoiesis in this age period. In infants with anaemia the available data are conflicting. ESF is produced as a response also to anaemic hypoxia, but preliminary data from this laboratory suggest that the $\mathrm{Hb}$ level at which ESF is increased may be lower at age 0 to 3 months than in adult life. This agrees with the observation that $\mathrm{Hb}$ levels down to 6 to $8 \mathrm{~g} / 100 \mathrm{ml}$ may occur before there is an increase in bone marrow erythroid activity or in peripheral reticulocytes (Hurdle and Davis, 1965).

Since we have seen that the regulation of erythropoiesis by ESF is functioning in late fetal life, and since hypoxic hypoxia stimulates ESF production during the first months, the lack of ESF response at $\mathrm{Hb}$ levels that are low by adult standards is probably not due to unresponsiveness of the ESF regulatory system, but rather to one or more of the adaptive mechanisms described previously, which secure that the tissues obtain sufficient oxygen.

Present data indicate that ESF production ceases at birth, though in view of the low sensitivity of the methods used this conclusion needs to be a tentative one. Erythropoiesis continues, however, though at a low rate, so that if it is correct that ESF production stops at birth, the continuance of erythropoiesis in the first months indicates that at this age period there is a 'basal' erythropoiesis 
which is not regulated by ESF. Experiments in newborn rats indicate that erythropoiesis at this age is less dependant upon ESF (from the kidney) than in adult animals (Lucarelli et al., 1964), though since polycythaemia suppresses erythropoiesis in this age, the regulatory system must be functioning (Zaizov and Matoth, 1971).

From the third month of life increased ESF levels are again demonstrable in blood, and the red cell volume starts to rise at this time (Mann et al., 1965). These findings imply that the tissue oxygenation is again reduced and that there is an increased demand for red cells. The increased erythropoiesis is mediated through hypoxia at the site of $\mathrm{O}_{2}$ registration and increased ESF production. In spite of the speeded red cell formation from this third month with an increase in red cell volume, $\mathrm{RCV} / \mathrm{kg}$ does not increase (Bratteby, 1968), the infant's growth rate tending to exceed the rate of red cell formation.

In premature infants the postnatal drop in $\mathrm{Hb}$ concentration and total RCV is more obvious than in the term infants. No data concerning ESF levels are available, but based on reticulocyte studies in premature infants (Seip and Halvorsen, 1956), one would expect that the increase in ESF production would occur earlier in premature infants than in term infants, and earlier the smaller the infant is. Why the $\mathrm{Hb}$ level falls lower than in term infants is unknown, but it is likely to be due to the same adaptive mechanisms as in term infants. A support for the adaptation theory is that the shift in oxyhaemoglobin equilibrium is far more gradual in premature than in term infants, adult levels being achieved late in the first half year of life (Delivoria-Papadopoulos et al., 1971). A bone marrow insufficiency in the premature infants is a possibility but unlikely, since the reticulocyte response is higher and starts earlier the smaller the infant.

\section{Conclusions}

At the yolk sac stage, the regulation of fetal erythropoiesis is not known. At the hepatic and myeloid stage the hormone, erythropoietin, participates in the regulation. The normally occurring polycythaemia present at birth is a result of increased erythropoietin production. After birth, tissue oxygenation improves, erythropoietin production ceases and erythropoiesis is reduced. During the period of low Hb levels at 2 to 3 months of age, the regulatory system also seems to be intact, but geared to a lower level of $\mathrm{Hb}$ concentration than later in life, as a result of intraerythrocytic changes which facilitate tissue oxygenation, and thus reduce the need for circulating haemoglobin. The shift from $\mathrm{Hb}-\mathrm{F}$ to $\mathrm{Hb}-\mathrm{A}$ and the increase in red cell 2,3-diphosphoglycerate are the most important factors, but it is still a matter of dispute whether the change in $2,3-D P G$ is a primary or secondary mechanism.

\section{REFERENCES}

Basch, R. S. (1972). Hemoglobin synthesis in short-term culture of human fetal hemopoietic tissues. Blood, 39, 530 .

Battaglia, F. C., Bowes, W., McGaughey, H. R., Makowski, E. L. and Meschia, G. (1969). The effect of fetal exchange transfusions with adult blood upon fetal oxygenation. Pediatric Research, 3, 60.

Bertles, J. F. (1970). Occurrence and significance of fetal hemoglobins. In Regulation of Hematopoiesis, Vol. 1, p. 731. Ed. by A. S. Gordon. Appleton-Century-Crofts, New York

Bratteby, L. E. (1968). Studies on Erythro-kinetics in Early Infancy. (Acta Universitatis Upsaliensis. Abstracts of Uppsala Dissertations in Medicine, 47). Söderström and Finn, Uppsala.

Cole, R. J., and Paul, J. (1966). The effects of erythropoietin on haem synthesis in mouse yolk sac and cultured foetal liver cells. Fournal of Embryology and Experimental Morphology, 15, 245.

Delivoria-Papadopoulos, M., Poncevic, N. P., and Oski, F. A (1971). Postnatal changes in oxygen transport of term, premature, and sick infants: the role of red cell 2,3-diphosphoglycerate and adult hemoglobin. Pediatric Research, 5, 235.

Finne, P. H. (1964). Erythropoietin levels in the amniotic fluid, particularly in Rh-immunized pregnancies. Acta Paediatrica, 53, 269.

Finne, P. H. (1966). Erythropoietin levels in cord blood as an indicator of intrauterine hypoxia. Acta Paediatrica Scandinavica, 55, 478.

Gairdner, D., Marks, J., and Roscoe, J. D. (1952). Blood formation in infancy. II. Normal erythropoiesis. Archives of Disease in Childhood, 27, 214.

Garby, L., Sjölin, S., and Vuille, J. C. (1962). Studies on erythrokinetics in infancy. II. The relative rate of synthesis of haemoglobin $\mathbf{F}$ and haemoglobin $\mathrm{A}$ during the first months of life. Acta Paediatrica, 51, 245.

Gordon, A. S. (1971). Annotation. The current status of erythropoietin. British fournal of Haematology, 21, 611.

Gordon, A. S., and Zanjani, E. D. (1970). Some aspects of erythropoietin physiology. In Regulation of Hematopoiesis, Vol. 1, p. 413. Ed. by A. S. Gordon. Appleton-Century-Crofts, New York.

Halvorsen, S. (1963). Plasma erythropoietin levels on cord blood and in blood during the first weeks of life. Acta Paediatrica, 52, 425.

Halvorsen, S., and Finne, P. H. (1968). Erythropoietin production in the human fetus and newborn. Annals of the New York Academy of Sciences, 149, 576.

Hodgson, G. (1970). Mechanism of action of erythropoietin. In Regulation of Hematopoiesis, Vol. 1, p. 459 . Ed. by A. S. Gordon. Appleton-Century-Crofts, New York.

Humbert, J. R., Abelson, H., Hathaway, W. E., and Battaglia, F. C. (1969). Polycythemia in small for gestational age infants. Fournal of Pediatrics, 75, 812.

Hurdle, A. D. F., and Davis, J. A. (1965). The 'late' anaemia of haemolytic disease of the newborn. British fournal of Haematology, 11, 247.

Jacobson, L. O., Marks, E. K., and Gaston, E. O. (1959). Studies on erythropoiesis. XII. The effect of transfusion-induced polycythemia in the mother on the fetus. Blood, 14, 644.

Kalpaktsoglou, P. K., and Emery, J. L. (1965). The effect of birth on the haemopoietic tissue of the human bone marrow. British fournal of Haematology, 11, 453.

Krzymowski, T., and Krzymowska, H. (1962). Studies on the erythropoiesis inhibiting factor in the plasma of animals with transfusion polycythemia. Blood, 19,38 .

Lindemann, R. (1971). Erythropoiesis inhibiting factor (EIF). I. Fractionation and demonstration of urinary EIF. British fournal of Haematology, 21, 623. 
Lindemann, R., and Halvorsen, S. (1971). Excretion of erythropoietin and erythropoiesis inhibitors in normal infants and in infants with neonatal polyglobulia. Abstract, European Society for Pediatric Research, Brighton.

Lucarelli, G., Howard, D., and Stohlman, F., Jr. (1964). Regulation of erythropoiesis. XV. Neonatal erythropoiesis and the effect of nephrectomy. fournal of Clinical Investigation, 43, 2195.

Mann, D. L., Sites, M. L., Donati, R. M., and Gallagher, N. I. (1965). Erythropoietic stimulating activity during the first ninety days of life. Proceedings of the Society for Experimental Biology and Medicine, 118, 212.

Marks, J., Gairdner, D., and Roscoe, J. D. (1955). Blood formation in infancy. III. Cord blood. Archives of Disease in Childhood, 30, 117.

Moe, P. J. (1963). Iron requirements in infancy. Acta Paediatrica, 52, Suppl. 150.

Naets, J. P. (1960). The role of the kidney in the production of the erythropoietic factor. Blood, 16, 1770.

Nathan, D. C., Schupak, E., Stohlman, F., Jr., and Merrill, J. P. (1964). Erythropoiesis in anephric man. fournal of Clinical Investigation, 43, 2158.

Oski, F. A., and Delivoria-Papadopoulos, M. (1970). The red cell, 2,3-diphosphoglycerate, and tissue oxygen release. fournal of Pediatrics, 77, 941.

Schooley, J. C., Garcia, J. F., Cantor, L. N., and Havens, V. W. (1968). A summary of some studies on erythropoiesis using anti-erythropoietin immune serum. Annals of the New York Academy of Sciences, 149, 266.

Seip, M. (1955). The reticulocyte level, and the erythrocyte production judged from reticulocyte studies, in newborn infants during the first week of life. Acta Paediatrica, 44, 355.
Seip, M., and Halvorsen, S. (1956). Erythrocyte production and iron stores in premature infants during the first months of life. Acta Paediatrica, 45, 600 .

Skjælaaen, P., and Halvorsen, S. (1971). Inhibition of erythropoiesis by plasma from newborn infants. Acta Paediatrica Scandinavica, 60, 301.

Stohlman, F., Jr. (1970). Fetal erythropoiesis. In Regulation of Hematopoiesis, Vol. 1, p. 471. Ed. by A. S. Gurdon. Appleton-Century-Crofts, New York.

Thomas, D. B., and Yoffey, J. M. (1962). Human foetal haemopoiesis. I. The cellular composition of foetal blood. British fournal of Haematology, 8, 290.

Usher, R., and Lind, J. (1965). Blood volume of the newborn premature infant. Acta Paediatrica Scandinavica, 54, 419.

de Verdier, C. H., and Garby, L. (1969). Low binding of 2,3diphosphoglycerate to haemoglobin $F$ : a contribution to the knowledge of the binding site and an explanation for the high oxygen affinity of foetal blood. Scandinavian fournal of Clinical and Laboratory Investigation, 23, 149.

Walker, J., and Turnbull, E. P. N. (1953). Haemoglobin and red cells in the human foetus and their relation to the oxygen content of the blood in the vessels of the umbilical cord. Lancet, 2, 312.

Yoffey, J. M. (1971). The stem cell problem in the fetus. Israel fournal of Medical Sciences, 7, 825 .

Zaizov, R., and Matoth, Y. (1971). Regulation of erythropoiesis in the newborn rat. Israel fournal of Medical Sciences, 7, 846.

Zanjani, E. D., and Gordon, A. S. (1971). Erythropoietin production and utilization in fetal goats and sheep. Israel fournal of Medical Sciences, 7, 850. 